\title{
Problemas de método en el estudio de la oposición al franquismo. La utilización del testimonio oral
}

\author{
Alicia alted y Abdón Mateos
}

"Alguien iba leyendo los mensajes del interior, escritos por otras manos. Realmente habian llegado muchos, pero ninguno transmitía la sensación de verdad que tienen las palabras, la emoción del que te habla"

R. Rossanda

Lo primero que cabe señalar en unas consideraciones sobre la oposición al franquismo desde la óptica del testimonio de sus protagonistas, es el impacto emocional que produce esta experiencia en el historiador y en los propios entrevistados.

En efecto, la entrevista con personas cuya vida ha estado marcada por el exilio, la clandestinidad, la represión... implica, hasta cierto punto, la superación de toda barrera y distanciamiento. Inevitablemente se tiende a una empatia entre historiador y perseguido, al margen de que se compartan o no los puntos de vista político-ideológico de este último.

\footnotetext{
'Rossada, Rossanda, Un viaje inútif. Barcelona, Laia, 1984, págs. 131-132.
} 
Por ello, la elección de un tema de investigación como el que nos ocupa requiere asumir desde el principio un cierto compromiso político o, al menos, ético, puesto que se trata de estudiar una de las parcelas de nuestra historia contemporánea reciente que encierra mayores dificultades tanto desde un punto de vista epistemológico como de contenido.

\section{PERSPECTIVAS TEÓRICAS}

Con las presentes reflexiones no pretendemos reseñar el «martirologio" de los derrotados en la guerra civil, y menos presentar su resistencia como una epopeya, sino que intentamos enmarcar correctamente el tema de la oposición en el ámbito de nuestra historia política y social.

Realizar estudios sobre las fuerzas de la oposición antifranquista lleva consigo una serie de problemas que, aunque son comunes en todo análisis de organizaciones políticas y sindicales al margen de acotaciones de espacio y tiempo, en nuestro caso si incidencia es mayor debido a la cercanía temporal y al contexto político dictatorial.

En primer lugar, hay que se conscientes de que la historia de la oposición constituye una fuente de legitimación democrática para los grupos y organizaciones clandestinas o en el exilio. En esta línea y como señala Haupt, unos y otros tienden a elaborar una versión oficial de su pasado, pues no en vano éste constituye a la vez fuente de legitimidad e instrumento de legitimación ${ }^{2}$. Visión del pasado convertida en crónica militante, cuya misión consiste en forjar identidades que den cohesión interna y en demostrar continuidades de lineas políticas.

En segundo lugar y partiendo del riesgo evidente de tergiversación en aras de una legitimidad democrática, el historiador puede contribuir, consciente o inconscientemente, a deformar la memoria colectiva, sobre todo al acercarse al fenómeno de la clandestinidad. Aún cuando determinados grupos tuvieran su dirección y secciones organizadas en el exilio, al investigador le asalta la duda de si es posible reconstruir con objetividad y rigor unas actividades secretas. ¿Se pueden aplicar aquí categorias y conceptos válidos para otras situaciones históricas? ¿Existieron organizaciones de masas que apoyaban esa actividad clandestina o bien sólo se puede hablar de grupos clandestinos compuestos por cua-

2 HAUPT, G., El historiador y el movimiento social. Madrid, Siglo XXI, 1986, págs. 14- 
dros? ¿Cuál fue el significado de la pervivencia de los grupos políticos y sindicales en el exilio? ...

Estas dudas conceptuales se ponen de manifiesto enseguida al tomar contacto con protagonistas de los hechos. Por ejemplo, al conservar con miembros - ¿militantes, afiliados, simpatizantes?- de una formación ilegal, incluso residentes en el mismo espacio geográfico, se observa que no sólo sus experiencias difieren radicalmente sino que también su sensibilidad ante los acontecimientos es muy diferente. Esta distancia se acentúa cuando contrastamos información procedente de personas adscritas a distintas organizaciones. Por tanto, existe una fragmentación de trayectorias inherente a la dictadura, y cruzada por cortes geográficos $y$ sociogeneracionales, que dificulta notablemente el desarrollo de la historiografía.

Otro problema que se plantea está relacionado con el grado de concienciación histórica. Entre el militante comprometido que supedita toda su experiencia vital a una "causa" y la persona que inmersa en su cotidianeidad protesta ante situaciones conflictivas que le afectan personalmente, hay toda una gradación muy compleja en sus matices. En el caso de la oposición antifranquista este escalonamiento se puede seguir muy bien analizando la distinta percepción del fenómeno de la protesta reivindicativa de carácter económico y de la huelga.

En ese mismo orden de cosas, pero desde otra óptica, hay que tener en cuenta los factores de persistencia o de superación consciente (no de olvido) de la memoria histórica. Así, un mismo acontecimiento que ha marcado profundamente a toda una comunidad, es asumido de manera muy diversa por los integrantes de la misma. Hoy en día todavía podemos encontrarnos con hombres y mujeres que no han podido y no han querido superar el hecho de la guerra civil y la manera como ésta incidió en sus vidas. En el otro extremo, nos encontramos con personas que mantuvieron actitudes de oposición (por ejemplo un exilio testimonial), pero que, sin embargo, rehicieron sus vidas con un deseo voluntario de superación del trauma de la guerra. Esta distinta actitud con todos los matices que encierra, incide como es obvio en la manera de transmisión de la memoria histórica a las nuevas generaciones.

Un último problema al que nos referiremos es el que se puede denominar "deformación presentista". La historia de la oposición es una historia de vencidos. Primero en 1939, luego en la posguerra y, una vez más, derrotados por la forma en que se produjo el final de la dictadura. Pero es indudable que hubo unas formaciones más derrotadas que otras, en la medida en que algunas lograron sobrevivir a lo largo de varias 
décadas y representar de nuevo a porciones importantes de la sociedad en el régimen democrático. En este sentido, se puede correr el riesgo de escoger como objetos de investigación movimientos y organizaciones predominantes hoy en dia o problemáticas actuales, pero ajenas a la realidad del franquismo. En otras palabras, proyectar la preocupaciones y problemas del presente sobre el inmediato pasado, minusvalorando o dejando de lado las que en su momento fueron realmente importantes. Otra cosa muy distinta es realizar interpretaciones de ese pasado con la ayuda de las nuevas luces que nos da el presente.

Junto a estos problemas que se deben tener en cuenta en un acercamiento al estudio de la oposición antifranquista, hay otros aspectos que no podemos ignorar porque constituyen el entramado metodológico que hace inteligible el fenómeno objeto de estudio.

Así y desde un punto de vista interno, la historia de las fuerzas de la oposición podría realizarse en varios niveles. No nos referimos a ámbitos sectoriales o geográficos de actuación, sino a áquel aspecto que constituye la mediación entre objetivos y prácticas, entre ideología y táctica: el modelo organizativo. A menudo se reduce el análisis de una organización a lo que ocurre con sus dirigentes, con sus líderes. Pero aunque en el estudio de un partido o de un sindicato el poder interno constituye un aspecto esencial, no se puede olvidar que existen también unas estructuras de base; unas secciones locales y unos militantes que conforman el cuerpo de una organización. Incluso para el período que nos ocupa los simpatizantes y los antiguos afiliados supusieron una parcela primordial para el estudio de una organización. Ésto nos acerca a las relaciones existentes entre la minoría organizada y los grupos sociales a los que representó y pretendía movilizar de cara a un futuro.

Por otra parte, el estudio de la oposición al franquismo, de sus formaciones políticas y grupos sindicales ilegales, no puede constituirse en objeto de investigación aislado. Estamos en una época de la historia del mundo occidental en la que se produce una transición convulsa desde el orden liberal-burgués a otro que simplificando podriamos calificar de democrático y social. Una transición con muchos altibajos en la Península Ibérica y en Latinoamérica. Hay, pues, rasgos generales comunes con otros regímenes dictatoriales y sus respectivas oposiciones politicas y resistencias sociales. Por ello, aún cuando estudiemos monográficamente una determinada organización conviene tener en cuenta las relaciones e influencias con grupos de similar tendencia ideológica de otros países.

Desde nuestra particular perspectiva, investigar una organización obliga a considerar sus relaciones con otras formaciones de la oposición, 
con las fuerzas e instituciones sociales, e incluso con el poder establecido. En efecto, las relaciones existentes entre el poder y las distintas oposiciones permiten establecer tipologias, que responden a periodos diferentes de la dictadura. Por ello, una misma organización puede ser clasificada según las épocas dentro de varios tipos de oposición.

En términos generales, la resistencia clandestina afecta a la totalidad de las organizaciones derrotadas en la guerra y perdura hasta el final del decenio de los cincuenta. En cambio, en los años sesenta algunas formaciones optaron por una salida parcial de la clandestinidad para poder influir en la configuración de un tejido democrático en la sociedad, y las que mantuvieron criterios organizativos muy cerrados, sólo desde una perspectiva subjetiva e interna se las podria considerar clandestinas. Por otro lado, la mayoría de los nuevos grupos de oposición moderados o "centristas" disfrutaron desde sus orígenes de una relativa tolerancia oficial, como también ocurrió con disidentes y "neos" respecto a las formaciones históricas. Esta oposición alegal y parte de la ilegal, mantuvo una serie de contactos con los "evolucionistas" o "reformistas" desde dentro del sistema. Por ejemplo, hubo intentos por parte de éstos últimos de integrar a parte de la oposición política y de la protesta social en el seno del franquismo bien a través de una Organización Sindical (OSE) reformada, bien mediante proyectos de ley de asociación política dentro del Movimiento. No obstante, los contactos oficiosos no excluyeron otro tipo de relaciones entre el poder y esta oposición, pues sus miembros sufrieron en mayor o menor medida algún tipo de represión. $Y$ es que la negociación entre el poder establecido y la oposición democrática para restaurar las libertades solo pudo producirse después de la muerte de Franco.

Aparte de las distintas formas de relación entre poder y oposición (represión, contrapropaganda, integración, compromiso), se podrían invertir los términos y analizar las estrategias y tácticas de lucha de la oposición frente al poder. Antinomias tácticas como las de resistencia armada - posición pacífica; subversión clandestina - infiltración; acción internacional desde el exilio - lucha en el interior, unidad de fuerzas- exclusión de organizaciones; simbolizan algunas de las opciones principales que tuvo que adoptar la oposición. En este juego de combinaciones cabría considerar las relaciones de las fuerzas de la oposición con miembros de instituciones como el Ejército y la Iglesia. Sobre todo en el segundo caso pues, como es conocido, en los años sesenta los movimientos de Acción Católica se convirtieron en lugares de concienciación democrática y parte del clero se sumó a las actividades de la oposición. 
Por último, las minorias organizadas que constituyeron la oposición, -incluso comisiones obreras o el movimiento estudiantil nunca superaron el carácter de amplias vanguardias-, forman parte de determinados grupos y clases sociales, y pretenden movilizarlos y representar sus intereses. Por ello, un aspecto crucial del estudio de la trayectoria de estos partidos y sindicatos ilegales es su presencia en la sociedad. Algo que no se reduce, obviamente, a número de militantes y simpatizantes sino que se expresa mucho mejor con el concepto de implantación. Se trata de conocer hasta qué punto unas élites políticas son capaces de dirigir y encauzar la protesta social, de impulsar una toma de conciencia democrática.

A veces se trata también de una repercusión negativa, en la medida en que las actividades de la resistencia antifranquista provocaron reacciones represivas e indiscriminadas de la dictadura contra la parte de la sociedad que se vio envuelta en ellas. De todas formas, estas consecuencias negativas tuvieron un carácter limitado tanto cronológica como espacialmente. Por ejemplo, la guerrilla en áreas rurales poco pobladas en los cuarenta y cincuenta, o con otro carácter, la violencia en el País Vasco en los últimos años de la dictadura.

En suma, el análisis del tema de la oposición al régimen de Franco incumbe esencialmente a la historia política. Una historia entendida como un conjunto de interrelaciones entre el poder, la oposición y la sociedad; que se desarrolló tanto en el interior de España como en el exilio.

\section{LA FUENTE ORAL Y EL ESTUDIO DE LA OPOSICIÓN ANTIFRANQUISTA}

Hoy en dia se acepta comúnmente en el ámbito historiográfico el valor que posee el testimonio oral para el análisis de la historia más reciente. En realidad, no se concibe ésta sin el testimonio y, de forma paralela, la fuente oral (dejamos al margen el tema de la transmisión oral de la memoria colectiva, o sea, lo que conforma la tradición) tiene en buena medida su razón de ser dentro de este marco de lo contemporáneo o de la contemporaneidad.

Ahora bien, no se puede perder de vista que aunque ambas facetas se complementan son de naturaleza muy diferente. El problema surge cuando se pretende identificar la historia con el testimonio oral. En realidad, el testimonio es una fuente para el conocimiento y análisis de 10 histórico y, como toda fuente, exige una metodologia y unas técnicas 
específicas que en este caso han sido tomadas de otras ciencias sociales: Sociología, Antropología, Etnologia...; aunque en el tratamiento del testimonio oral como fuente histórica se tienen que tener en cuenta una serie de variables propias de la investigación histórica.

El interés fundamental de la fuente oral es que nos permite hacer "otro tipo de historia", al abrir perspectivas y posibilidades en campos donde las informaciones procedentes del documento escrito son muy parcas o inexistentes.

Así, el ámbito de lo cotidiano es el dominio del testimonio, pero lo cotidiano no entendido con un carácter restrictivo. Es en el mundo de las creencias, percepciones...; en todo el complejo entramado de las mentalidades, donde el testimonio se revela como una fuente a la par que instrumento valioso de análisis ${ }^{3}$.

Con respecto al tema que nos ocupa, el testimonio puede servir para acercarnos al ambiente de la clandestinidad o del exilio, para conocer las actitudes, los valores, o en otros términos, la representación que del orden social y político tuvieron los miembros de la oposición. A este respecto, el investigador puede descubrir a su través la existencia de una serie de culturas políticas que, por encima de las más nítidas diferenciaciones y adscripciones político-ideológicas, identifican a sectores de esa oposición.

Por las propias condiciones de clandestinidad y exilio, el testimonio suple en mayor medida que para otros periodos históricos la carencia de fuentes escritas. Es indudable que la fuente oral tiene un importante papel que cumplir en la reconstrucción de la realidad de estructuras organizativas clandestinas tanto en un plano central o estatal como, sobre todo, en lo que se refiere a la trama orgánica de carácter local o sectorial. El conocimiento de esa realidad orgánica nos puede hacer comprender hasta qué punto existia una adecuación entre discurso y propaganda políticas, y la táctica y acciones concretas realizadas por las fuerzas de la oposición. Pues bien, para conocer el funcionamiento de las organizaciones, las relaciones entre las distintas instancias orgánicas y la forma de tomar las decisiones, es indudable que la fuente oral nos presta una ayuda inestimable.

\footnotetext{
${ }^{3}$ Véase ALTED, Alicia. «El testimonio oral como fuente histórica. Aproximación metodológica", Perspectiva Contemporánea. España Siglo xx, núm. 1. Madrid, octubre de 1988, págs. 155-162.
} 
El documento oral no sólo completa las carencias de las fuentes de archivo y hemerográficas sino que en el caso de las nuevas organizaciones surgidas en la segunda mitad de la dictadura constituye a menudo la fuente principal cuando no única de que se dispone. Este hecho quizás haya contribuido a que la historiografia sobre esa nueva oposición prácticamente este en sus inicios. En efecto, las nuevas formaciones políticas y grupos sindicales al no tener sus direcciones en el exilio generaron menos documentos escritos y los conservaron peor que las organizaciones históricas. Por otra parte, los grupos de orientación moderada en escasa medida desarrollaron la infraestructura orgánica propia de un partido ilegal. Todo ello, ha revertido en que las fuentes de archivo conservadas de estas nuevas agrupaciones sean muy reducidas. En realidad, en el caso de grupos como los encabezados por Ridruejo, Tierno Galván, Giménez Fernández, Satrústegui y Gil Robles, tendría más sentido la biografía política del personaje que su estudio como partido. Una biografía "colectiva" de la personalidad estudiada que recogiese los testimonios de sus colaboradores.

Precisamente, la biografía de personajes relevantes de la oposición es uno de los terrenos que se pueden ver más beneficiados del testimonio oral. Sin embargo, parece que la tradición de los políticos españoles de no escribir sus memorias está acompañada en el campo historiográfico por un escaso interés por la biografía ${ }^{4}$.

Los militantes siempre constituyeron una pequeña minoría frente a la parte de la sociedad forzada al exilio y la represaliada en la posguerra. Minorías organizadas, vanguardias o élites políticas, que por supuesto pertenecian a una serie de grupos sociales, aunque en escasa medida los constituyeron por sí mismos. Bien es verdad que existieron grupos como los mineros asturianos, los metalúrgicos vizcaínos o los estudiantes universitarios de Madrid y Barcelona en los que una gran parte de sus miembros se vieron inmersos en protestas reivindicativas durante la segunda mitad del franquismo. Sin embargo, incluso respecto a estos grupos sociales, el grado del politización o de concienciación democrática no fue asimilable a la generalización de las protestas.

Por ello no se puede estudiar grupos de militantes como si formaran grupos sociales. $Y$ esta realidad dificulta una de las mayores posibilidades que ofrece la utilización sistemática del testimonio oral: la realización

"El número 2 "Memoria y biografia", de la revista Historia y Fuente oral recoge varios artículos en los que se aborda este tema de la utilización del testimonio oral para el análisis biográfico. Barcelona, 1989. 
de estudios de historia social y cultural. Porque cuando a través del testimonio obtenemos pistas sobre la cultura política de los protagonistas de la oposición nos estamos refiriendo a una cultura de élites políticas, sean de formación universitaria o trabajadores industriales. En todo caso, se pueden analizar las relaciones existentes entre, por ejemplo, la minoría organizada de comisiones obreras en el metal de Madrid y el conjunto de metalúrgicos madrileños, pero no identificar los valores y experiencias de los militares con los del conjunto de los trabajadores.

Abundando en esta idea, la historia de vida de un militante antifranquista puede aproximarse a la de la sociedad a la que pertenecia, pero sólo eso. En escasa medida, esa reconstrucción de experiencias de militancia, de trabajo o de familia, podrian reflejar el microcosmos de la historia de la sociedad bajo el régimen franquista en una comunidad local. Sobre todo porque las consecuencias represivas que tuvieron para el militante esa actividad política en los planos del trabajo y de las condiciones de vida, le alejan del común de las experiencias. Por supuesto, la totalidad de la sociedad derrotada en la guerra sufrió este tipo de coerciones pero los “reincidentes» aún más. Existió, pues, un extrañamiento del militante clandestino o en el exilio respecto a la sociedad a la que se pertenecia.

En suma, de lo que se trata es de vincular la historia de la oposición al franquismo y, por tanto, de una lucha esencialmente política, con la sociedad de la que se procedia y a la que se pretendía movilizar, concienciar $y$, en un futuro democrático, representar libremente sus intereses. Y ello a través de la utilización de todas las fuentes disponibles, entre las que el testimonio oral se convierte en una de las más necesarias, sobre todo en el estudio del entorno clandestino inherente a cualquier tipo de oposición ilegal.

Desde una óptica metodológica y en relación con lo que se acaba de señalar, procede hacer unas observaciones sobre las técnicas de fijación del testimonio oral en el análisis de la oposición antifranquista.

Las técnicas más utilizadas en la recogida del testimonio de los protagonistas de la oposición son las del «informador estratégico» y la «historia de vida". La primera se aplica sobre todo cuando se pretende reconstruir la trayectoria general de una organización en España y/o en el exilio. Se trata de suplir las lagunas de las fuente de archivo, de comprobar hipótesis, de contrastar información confusa debido al carácter semisecreto de las actividades de la oposición. Buscamos, por tanto, una información cualitativa. 
La selección de los entrevistados con este tipo de técnica se suele circunscribir a los dirigentes, a las élites políticas ${ }^{5}$. No se pretende confeccionar una muestra representativa desde un punto de vista sociológico, sino que la representatividad viene dada por el lugar que ocupan las personas en la organización. El dirigente puede tener una experiencia que permita superar la fragmentación de la información que supone actuar bajo condiciones de ilegalidad.

En muchas ocasiones los mejores informadores no son necesariamente los máximos dirigentes, debido a la multiplicidad de tareas desempeñadas y a la dilatación de su experiencia política. Los miembros del "aparato", cuadros medios y liberados, pueden suministrar más datos sobre hechos concretos. Por el contrario, los líderes suelen tener elaborada una visión sobre su pasado y el de la organización a la que pertenecen. Este tipo de visiones si bien pueden ofrecer pistas en el comienzo de una investigación, en cambio, si las entrevistas se realizan al final del estudio no sirven más que para comprobar interpretaciones personales.

Hoy en día, debido al efecto conocido como "life review", los informadores más interesantes son los que proceden de las generaciones de jóvenes y niños de la guerra civil. Por razones de edad, protagonizaron la resistencia de la guerra y posguerra, ocupando puestos de dirección en la segunda mitad del franquismo. En cambio las generaciones más recientes a menudo han tenido experiencias políticas más intensas en el régimen actual por lo que sus recuerdos sobre la oposición a la dictadura son menos consistentes. Además, el hecho de existir un importante grado de movilidad y trasvase de militantes debido a la desaparición de organizaciones, escisiones y predominio de otras, en la actualidad, distorsiona los recuerdos de los protagonistas. Esto ocurre tanto entre los militantes que hoy ocupan puestos de responsabilidad como en el caso de los que fueron marginados o se automarginaron de la acción política en democracia. Los primeros, son informadores utilizados por otros profesionales, hecho que repercute negativamente en su interés como fuente histórica. Sus compromisos políticos les hace dar una versión curricular, anecdótica y reelaborada de su pasado.

Algo parecido sucede con los escasos dirigentes vivos que ya durante la república ocuparon puestos de cierta responsabilidad. En estos casos suelen predominar los recuerdos sobre el período republicano más

${ }^{5}$ Sobre la metodología del :estimonio de los dirigentes políticos consúltense: SELdON, A. Y PAPPWORTH, J. By word of mouth. "Elite" oral history. Londres, Methuen, 1983; y DEXTER, L. A. Elite and specialized interviewing. Northwestern, University Press, 1970. 
que sobre la posguerra. La aceleración histórica de los años treinta y de los setenta, repercute negativamente en la conservación de recuerdos para los decenios intermedios entre las élites políticas que ha vivido activamente la república, guerra civil y transición a la democracia.

Por último, la técnica de la historia biográfica es de mayor utilidad para las investigaciones que se ocupan de la trayectoria de la oposición en un ámbito geográfico limitado, pues en estos casos se debe descender al testimonio de los militantes de a pie. Por ejemplo, esta técnica nos permite estudiar procesos de socialización política en los marcos de la familia, del trabajo y del barrio. Asimismo, para conocer el sistema de valores que identificaba a los miembros de las organizaciones antifranquistas, su cultura política, es indudable que la "historia de vida" constituye una técnica adecuada.

\section{BREVES NOTAS SOBRE EL «ESTADO DE LA CUESTIONN"}

Realizar un balance en torno a la utilización de la fuente oral en la historiografía de la oposición al franquismo se convierte, en realidad, en una presentación del "estado de la cuestión" general sobre el tema. Prácticamente casi todos los «especialistas» sobre la oposición utilizan en mayor o menor medida el testimonio de los protagonistas. El diferente grado depende del objeto de la investigación y de la existencia de otro tipo de fuentes.

Los primeros estudios sobre la oposición al franquismo fueron realizados por los propios militantes de organizaciones o bien por personas no vinculadas directamente a una organización política o sindical, pero que por su compromiso político se vieron obligadas a la clandestinidad o al exilio. Estos escritos presentan sólo en algún caso carácter estrictamente autobiográfico. En su mayoria, los autores hacen uso de sus propias vivencias para aproximarse a la trayectoria de las organizaciones 0 para reconstruir retazos de la vida en el exilio (en los campos de refugiados franceses, en la resistencia... ) o en la clandestinidad y en las cárceles. Quizá sea el movimiento libertario el sector de la oposición "histórica" que cuenta con más escritos realizados por militantes y simpatizantes. Cenetistas como Molina, Damiano, Marco Nadal, Paz, Miró y Gómez Casas, entre otros, intentaron reconstruir la trayectoria de la CNT basándose en sus experiencias, las de otros libertarios, y colecciones documentales. 
A este nivel, que hoy en día continúa vivo con los libros de memorias y recuerdos, se superpusieron otros dos de manera sucesiva.

En primer lugar los estudios realizados por periodistas, sociólogos, politólogos... basados en testimonios orales y fuentes impresas de los grupos de la oposición, y en los ejemplos, los trabajos de J. M. Maravall, R. Fishman, G. Jaúregui, P. Lizcano, J. M. Colomer, F. Jaúregui y P. Vega...

En segundo término, los trabajos elaborados por historiadores que utilizan procedimientos heurísticos propios de la ciencia histórica. La información exhaustiva y la contrastación de fuentes son algunos de los aspectos que definen su quehacer. No obstante, los primeros trabajos publicados en los años setenta por historiadores que se ocuparon de esta problemática se basaron casi con exclusividad en el testimonio oral y en la prensa clandestina o del exilio, debido a la dispersión e innacesibilidad de los archivos públicos y privados. Sólo en los últimos años han comenzado a aparecer investigaciones cuyo soporte principal es la documentación de archivo ${ }^{6}$.

En suma y como recapitulación, el documento oral constituye una fuente de extraordinario interés para el análisis del tema eje de estas reflexiones, por las especiales características del mismo. Ahora bien, como toda fuente histórica presenta una serie de limitaciones, de ahí la necesidad de su contrastación con otras fuentes escritas, gráficas o icónicas. Lo que no consideramos factible es hacer "historia oral", en nuestro caso concreto, de la oposición al régimen franquista.

${ }^{6}$ Véase MATEOS, Abdón, "Organizaciones, luchas y culturas obreras bajo el franquismo. Consideraciones en torno a la bibliografía reciente", Perspectiva Contemporánea. España. Siglo xx, núm. 1. Madrid, octubre de 1988, págs. 263-272. 